\title{
Ativos e aportes do cooperativismo ao desenvolvimento regional: um olhar regional, do local para o global
}

\author{
Assets and contributions from cooperatives to regional development: cooperative \\ Support for Regional Development: A regional look, from local to global
}

\begin{abstract}
Resumo
Este estudo versa sobre o cooperativismo e seus impactos no desenvolvimento, tomando por base uma região. O objetivo desse estudo é o de mapear ativos e aportes positivos no processo de desenvolvimento da região Missões-Noroeste do Estado do Rio Grande do Sul. Em termos de metodologia, a pesquisa caracteriza-se como estudo de caso, qualitativa, documental e de campo, de natureza exploratória e descritiva (STUMPF, 2005). As fontes abrangem documentos, publicações, entrevistas, observação direta e pesquisa participante. $\mathrm{O}$ estudo reconhece as desigualdades inter e intrarregionais, destacando a região Missões-Noroeste, e o cooperativismo ao longo da evolução tem jogado papel importante no processo de desenvolvimento da região. $\mathrm{O}$ estudo confirma que as prioridades e ações das cooperativas, com limitadas práticas de intercooperação e de agregação de valor as cadeias produtivas, poderiam ser significativamente maiores. Apesar de algumas limitações e dificuldades, as cooperativas vem cumprindo com os fundamentos da sua própria natureza que é o de contribuir com a dinâmica e no processo de desenvolvimento econômico e social da região.
\end{abstract}

Palavras-chave: cooperativismo, desenvolvimento regional, missões.

\begin{abstract}
This study deals with cooperativism and its impacts on the regional development. The aim of this study is to map assets and positive inputs in the development process of the Missions-Northwest region of the state of Rio Grande do Sul. In terms of methodology, the research is characterized as a case study, qualitative, documentary and field, exploratory and descriptive in nature (STUMPF, 2005) The study recognizes inter and intraregional inequalities, highlighting the Missions-Northwest region, and cooperative evolution has played an important role in the region's development process. The study confirms that the priorities and actions of cooperatives, with limited intercooperation practices and little value added to production chains, could be significantly higher. Despite some limitations and difficulties, the cooperatives have been complying with the fundamentals of their own nature, which is to contribute to the dynamics and process of economic and social development in the region.
\end{abstract}

Keywords: cooperativism, regional development, missions.

Ariosto Sparemberger ${ }^{\text {I }}$, Bruno Nonnemacher Büttenbender ${ }^{\text {II }}$, Dionatan Perdonsini ${ }^{\text {III }}$, Luciano Zamberlan ${ }^{\text {IV }}$, Pedro luís Büttenbender ${ }^{V}$.

${ }^{\text {I }}$ UNIJUI Universidade Regional do Noroeste do Estado do Rio Grande do Sul. IjuÍ, RS. ariosto@unijui.edu.br

${ }^{\text {II }}$ UNIJUI Universidade Regional do Noroeste do Estado do Rio Grande do Sul. IjuÍ, RS. brunobuttenbender@gmail.com

${ }^{\text {III }}$ UNIJUI Universidade Regional do Noroeste do Estado do Rio Grande do Sul. IjuÍ, RS. dionatanperdonsini@hotmail.com

${ }^{\text {IV }}$ UNIJUI Universidade Regional do Noroeste do Estado do Rio Grande do Sul. IjuÍ, RS. dionatanperdonsini@hotmail.com

${ }^{\text {V } U N I J U I ~ U n i v e r s i d a d e ~ R e g i o n a l ~ d o ~ N o r o e s t e ~ d o ~ E s t a d o ~ d o ~ R i o ~ G r a n d e ~ d o ~ S u l . ~ I j u I ́, ~ R S . ~ p l b u t t e n @ g m a i l . c o m ~}$ 


\section{Introdução}

No momento em que o mundo experimenta um processo de profundas transformações, e que as sociedades regionais passam a estabelecer relações globalizadas, o liberalismo de mercado se expressa diretamente pela competitividade e o triunfo de novas relações entre os indivíduos. As regiões estão experimentando novas formas de organização, e o cooperativismo vem se consolidando como alternativa de organização econômica e social em nível regional e, territorialmente, de forma mais ampla (DALLABRIDA e BÜTTENBENDER, 2007).

Este estudo resulta de um projeto de pesquisa, sustentado em uma rede de cooperação de pesquisadores de abrangência internacional que possui objetivo de estudar a gestão e governança das organizações cooperativas da região Missões-Noroeste do Rio Grande do Sul, direcionado ao fortalecimento, sustentabilidade, inovação e intercooperação, e contribuições para o desenvolvimento regional. Esta região selecionada como referência do estudo se justifica pelas raízes históricas que indicam para às primeiras experiências cooperativas na América Latina terem ocorrido nesse território ( MASY, 1992), a presença de significativo número de cooperativas, em vários segmentos, e a sua representativa importância no tecido de organização econômica e social da região. Por isto, o objetivo deste estudo é o de mapear ativos e aportes positivos no processo de desenvolvimento da região Missões-Noroeste do Estado do Rio Grande do Sul. Atendendo a questão sobre a importância das cooperativas na geração de empregos, dinamização econômica e inovação tecnológica em atividades produtivas, influencias na geração do valor adicionado dos municípios e as repercussões na manutenção das políticas públicas.

No processo de exaustão dos modelos tradicionais de sociedade, as pessoas através das diversas maneiras de organização passam a buscar novas formas de definições para a organização do trabalho e da geração de renda. Este contexto está gerando mudanças e atribuindo novos papéis para as instituições, sejam eles de cunho social, políticos, culturais ou econômicos. Por extensão, isto também se atribui para o Estado e, por conseguinte, para as sociedades expressas através dos seus governos, nos diversos níveis. O terceiro setor se agrega aos demais e passa a apresentar formas de organização da sociedade e da construção de respostas para as necessidades de grupos de pessoas.

O Cooperativismo tem se apresentado, na sociedade pós-moderna, como uma das formas mais inovadoras de organização do trabalho e da distribuição mais igualitária do poder e da renda. Surgido formalmente na segunda metade do século passado, auge da Revolução Industrial, o cooperativismo tem assumido formas e papeis cada vez mais importantes no desenvolvimento da sociedade. Estes papéis estão diretamente ligados a organização das pessoas, na qual elas próprias são os agentes do processo de construção da cidadania. Outras vezes o cooperativismo, na sua história, tem sido utilizado como instrumento para a implantação de projetos públicos e ou privados, complementando diferentes papeis no seu contexto.

O Cooperativismo, em um contexto geral, está estreitamente vinculado a história do desenvolvimento de regiões, como no caso da Região Missões-Noroeste do Rio Grande do Sul . Do período do processo de colonização aos dias atuais, o cooperativismo tem cumprido com papéis extremamente decisivos para a organização produtiva e de serviços, nos diversos setores, em especial o econômico, e nele o agrícola. Considerando o século XX, o cooperativismo da região inicialmente esteve presente de forma mais significativa na organização da produção primária (produção agrícola) e do Crédito e, posteriormente, nos setores de infraestrutura elétrica, de saúde, abrangendo ambientes rurais e urbanos. Atualmente as cooperativas estão presentes nos diversos setores da sociedade local-regional e global. 


\section{Antecedentes na Literatura}

O cooperativismo possui seus referenciais histórico-evolutivos sustentados em distintos fundamentos. Uma definição geral indica que o cooperativismo tem as suas origens integradas a própria origem do homem e de sua evolução. Como descreve Reisdorfer (2014) que o cooperativismo emerge desde os primórdios quando o homem passou a viver em grupos, e muitos exemplos de cooperação surgiram quando a humanidade passou a vier crises sociais, econômicas e políticas.

Uma abordagem distinta sobre as origens do cooperativismo na América Latina, fundamentada nas essências históricas de organização ibero-luso-americanas, sustenta que a origem do cooperativismo se deu com a formação das Reduções Jesuítico-Guaranis, localizadas na região das missões e fronteira entre os países do Paraguai, Argentina e Brasil (MASY, 1992). Um estudo aprofundado e resgate da história do cooperativismo, aproxima as origens do cooperativismo na América Latina, em especial no Brasil, especificamente no território missioneiro. Este que, que por definição constitui o atual território Missõe-Noroeste, que é o espaço geográfico prioritário desta pesquisa (BÜTTENBENDER, 2010a).

O cooperativismo moderno, como detalhado por Schneider e Lauschner (1979) teve a sua origem durante o período da revolução industrial do século XIX, com a criação da Cooperativa dos Tecelões de Rochlade, na Inglaterra. Os mesmos autores também sustentam que as origens do cooperativismo no Brasil e na América Latina ocorrem no período da passagem do século XIX para o Século XX. Citam como exemplos as experiências cooperativas: a) em 1891 no Rio de Janeiro; b) em 1895 em Pernambuco; c) em 1897 em São Paulo; e d) em 1902 no Rio Grande do Sul, através da fundação da Cooperativa de Crédito de Nova Petrópolis.

A evolução do cooperativismo no Brasil e no RS foi intensa e rápida ao longo do século XX com forte vinculação a história e a dinâmica de colonização pelos imigrantes europeus, como afirmam Büttenbender, Rotta e Hofler ( 2010). Pela necessidade e cultura organizativa, colaborativa e associativa, os imigrantes tiveram no cooperativismo uma das suas estratégias para: a) fortalecimento econômico e social; b) a viabilização do crédito; investimentos nas estruturas produtivas; provisão dos mecanismos de comercialização e armazenagem; a construção da infraestrutura energética e de serviços elétricos.

O Cooperativismo no Brasil se estrutura em 13 ramos diferentes, conforme (OCB, 2010): Agropecuário; Crédito; Turismo e Lazer; Infraestrutura; Saúde; Educacional; Especial; Habitacional; Mineral; Serviços; Consumo; Trabalho e Produção. Segundo Veiga e Fonseca (2001) aproximadamente $1 / 6$ da população mundial está ligada ao movimento cooperativista, e este número demonstra que o cooperativismo tem sido o movimento socioeconômico mais importante do mundo. São destacadas como realizações de cooperativas no mundo: a) foram às cooperativas de eletrificação rural que levaram energia elétrica ao meio rural nos EUA; b) a metade da produção de açúcar na Índia vem de cooperativas; c) o segundo lugar do mundo em crédito agrícola está com as cooperativas de crédito agrícola na França; d) a maior parte dos bens essenciais é escoada por cooperativas agrícolas nos países africanos; e) no Canadá, em cada três habitantes, um é membro de alguma cooperativa; f) no mercado de abastecimento de alimentos na Europa, as cooperativas de consumo estão na frente em vários países, como Finlândia e Suíça ocupando os primeiros lugares; g) os maiores fabricantes de refrigerantes e eletrodomésticos na Espanha estão na região Basca, que integram o complexo cooperativo de Mondragon.

Evidencia-se que âmbito mundial, tanto nos países desenvolvidos quanto em desenvolvimento, nas nações capitalistas quanto socialistas, e também nos países do terceiro mundo, a cooperação não está somente consolidada, mas adquire cada vez maior importância, como uma das formas mais adequadas para suprir às necessidades e interesses da população.

Muitas vezes, desenvolvimento é confundido com crescimento econômico, que depende do consumo crescente de energia e recursos naturais. Esse tipo de desenvolvimento tende a ser 
insustentável, pois leva ao esgotamento dos recursos naturais dos quais a humanidade depende. Desses recursos depende não só a existência humana e a diversidade biológica, como o próprio crescimento econômico.

Para Dallabrida e Büttenbender (2007), um território depende cada vez menos de suas condições físico-naturais (clima, solo, relevo, recursos) ou de sua posição geográfica para se desenvolver. É importante reconhecer que cada região possui uma história, uma cultura, um patrimônio, uma estrutura econômica e política diferente. Sendo assim, não é possível imaginar que uma região possa determinar suas estratégias, utilizar seus recursos, definir seus produtos ou instituir seus planos da mesma forma que outra o faz, ou utilizando-se de uma determinada receita ou fórmula, pois estratégias e planos de desenvolvimento regional não são simplesmente transferíveis e adaptáveis de uma região para outra. Outros fatores como capacidade de promover a cooperação, a integração e alinhamento de organizações políticas, sociais, econômicas e tecnológicas das regiões, das competências humanas e organizacionais, da capacidade de elaborar e pactuar planos e a gestão estratégica de desenvolvimento, sustentado em organizações econômicas e produtivas que gerem valor e promovam o reinvestimento dos valores agregados na própria região. Neste sentido cada região possui uma história, uma cultura, um patrimônio, uma estrutura econômica e política.

Os mesmo autores afirmam que, através do cooperativismo, os principais objetivos das iniciativas de desenvolvimento local são: 1) Maior valorização dos recursos endógenos de cada âmbito territorial, com atividades relacionadas à diversificação produtiva e promoção de novas empresas locais; 2) Organização de redes locais entre atores públicos e privados, para promover a inovação produtiva e empresarial no território; 3) Estabelecimento de consórcios intermunicipais e parcerias público-privadas a fim de incrementar a eficácia e eficiência das atividades de desenvolvimento local; 4) Busca de novas fontes de geração de trabalho e renda e investimento para o local; 5) Promoção de novas atividades de desenvolvimento científico e tecnológico no âmbito territorial; 6) Criação de novos instrumentos de financiamento para atender às cooperativas e demais organizações do tecido empreendedor local-regional; 7) Superação das limitações do enfoque assistencialista implícito nos fundos de inversão social e nos programas de luta contra a pobreza; 8) Incorporação de políticas de promoção comercial de cidades para promover a competitividade sistemática territorial, a agregação de valor e a promoção do reinvestimento local-regional; 9) Busca de acordos estratégicos em relação aos bens ambientais e ao desenvolvimento regional.

Segundo Albuquerque (2004) os principais objetivos das iniciativas de desenvolvimento local são: 1) Maior valorização dos recursos endógenos de cada âmbito territorial, com atividades relacionadas à diversificação produtiva e promoção de novas empresas locais; 2) Organização de redes locais entre atores públicos e privados, para promover a inovação produtiva e empresarial no território; 3) Estabelecimento de consórcios intermunicipais a fim de incrementar a eficácia e eficiência das atividades de desenvolvimento local; 4) Busca de novas fontes de emprego e investimento para o local; 5) Promoção de novas atividades de desenvolvimento científico e tecnológico no âmbito territorial; 6) Criação de novos instrumentos de financiamento para atender às micro e pequenas empresas locais; 7) Superação das limitações do enfoque assistencialista implícito nos fundos de inversão social e nos programas de luta contra a pobreza; 8) Incorporação de políticas de promoção comercial de cidades para promover a competitividade sistemática territorial; e 9) Busca de acordos estratégicos em relação aos bens ambientais e ao desenvolvimento regional.

O desenvolvimento de uma região é um processo resultante da ação organizada de seus atores e instituições, que, historicamente, constroem alternativas de geração de trabalho e renda com vistas à melhoria da qualidade de vida de sua população. O desenvolvimento local está ligado a situações particulares de cada região, sua história, sua cultura e seus recursos naturais. Às vezes vem associado ao meio rural, não especificamente ao agrícola, mas a algo especificamente ligado ao conjunto dos fatores produtivos e de distribuição da produção agrícola e seus serviços. Na afirmação de Brose (2002) o desenvolvimento local caracteriza-se pelo conjunto de iniciativas de origem 
comunitária ou municipal, que beneficiam diretamente às pessoas e instituições envolvidas e que podem - ou não - alcançar uma abrangência regional.

O desenvolvimento local, para Buarque (2002) é entendido como um processo endógeno de mudança, que leva ao dinamismo econômico e à melhoria da qualidade de vida da população em pequenas unidades territoriais e agrupamentos humanos. Isso permite dizer que haverá uma participação efetiva da população na definição de seu rumo e sua forma de desenvolvimento, cuja organização que facilita esta dinâmica social é a cooperativa. Daí a interação e correlação entre o desenvolvimento local e a organização cooperativa, gerando resultados econômicos e sociais em benefício das pessoas em cooperação e das comunidades do seu entorno (SANTOS, 2002).

A construção do desenvolvimento local é fruto da participação efetiva da comunidade, cuja centralidade está no ser humano como sujeito, com as mais diversas possibilidades de realização quanto à forma, organização, mas tem na cooperação um princípio fundamental. Na relação entre cooperação e desenvolvimento local, Frantz (2003) diz que organizações cooperativas são fenômenos que nascem da articulação e da associação de indivíduos que se identificam por interesses ou necessidades, buscando o seu fortalecimento pela instrumentalização, com vistas a objetivos e resultados, normalmente, de ordem econômica. A cooperação é, em seu princípio constituinte, um acordo racional de sujeitos sobre algo, isto é, a economia. $\mathrm{O}$ acordo da cooperação diz respeito aos interesses e necessidades frente à produção e distribuição de bens e riquezas. No entanto, contêm elementos sociais, culturais e políticos, incorporados ao seu sentido econômico. Destes elementos decorre uma natureza local que permite reconhecer uma relação entre a organização e o funcionamento de uma cooperativa e o processo de desenvolvimento local.

Assim, pela via cooperativa, renasce o local como base do processo de desenvolvimento, pela via do fortalecimento econômico e organização social. Entre o desenvolvimento local e a natureza da organização cooperativa se constitui como expressão dos interesses e necessidades de seus associados, da comunidade e do território, como extensão de suas economias individuais, mas em cooperação. A cooperativa caracterizada pela associação e pela instrumentação empresarial existe uma aproximação e convergência no processo de desenvolvimento local-regional. As organizações cooperativas são reconhecidas como expressão das ações locais de desenvolvimento. Porém, mais que o local, a organização cooperativa carrega dentro dela a força política que permite recolocar o homem, a pessoa, e não apenas o capital e a economia de mercado, no centro da dinâmica da economia, da sociedade e do desenvolvimento (BÜTTENBENDER, 2010a).

\section{Procedimentos metodológicos}

Para responder as questões centrais desta pesquisa, é utilizado o método do estudo de caso, que é mais apropriado para estudos centrados em questões do tipo "como" e "por quê" (YIN, 2005), que são semelhantes às questões propostas para o problema a ser estudado. $\mathrm{O}$ estudo contempla o levantamento histórico de dados necessários ao longo do período alvo do estudo. $\mathrm{O}$ método concentra o foco no estudo da gestão e da governança das organizações cooperativas da região Missões-Noroeste, direcionado a mapear contribuições para o desenvolvimento regional. Para isto são tomados como referência as cooperativas vinculadas aos 13 ramos do cooperativismo. Destacamse nos ramos as respectivas cooperativas tomadas como referência: agropecuário a cooperativas Cotrirosa, Coopermil, Coopatrigo, Cotrimaio e Cotricampo; crédito as cooperativas Sicredi, Cresol e Unicred; e infraestrutura as cooperativas Cooperluz, Certhil, Cermissões e Ceriluz.

Esta pesquisa caracteriza-se como qualitativo, documental e de campo, de natureza exploratória e descritiva (STUMPF, 2005). A pesquisa que compreende estudo da gestão e da governança das organizações cooperativas da região Missões-Noroeste, visando ampliar as contribuições para o desenvolvimento regional, tomando por base referências de estudos anteriores sobre o cooperativismo na região (BÜTTENBENDER, 1994, 1995, 2010a, 2010b e 2011). As fontes de dados e informações foram documentais, como registros e publicações, impressas e digitais, 
baseadas na gestão, no cooperativismo, no desenvolvimento e outras. A pesquisa possui contribuições resultantes da observação direta e participante, devido à pela participação em atividades das cooperativas com seus dirigentes e associados e membros da equipe de pesquisa serem membros integrantes de cooperativas (LAKATOS e MARCONI, 2003).

A coleta de dados foi realizada através de entrevistas em profundidade com lideranças, gestores, técnicos e pesquisadores vinculados a gestão, ao cooperativismo da região e ao desenvolvimento. Também via grupos de foco envolvendo lideranças do cooperativismo e a participação em seminários envolvendo dirigentes, associados e funcionários de cooperativas. Em fontes secundárias, foram consultados documentos e registros de cooperativas, base de dados da FEE (FEE, 2015), universidades, prefeituras e outros órgãos públicos. A descrição e a análise dos dados envolvem as organizações cooperativas na Região Missões-Noroeste do Rio Grande do Sul, a identificação das experiências e práticas inovadoras de gestão e governança cooperativa e identificação de contribuições do cooperativismo ao desenvolvimento regional.

\section{Resultados}

O processo evolutivo do cooperativismo na região pode ser visto e reconhecido em distintas fases, sendo que em cada uma delas gerou múltiplos aportes ao desenvolvimento. Nos antecedentes, observando o espaço territorial da fronteira do Brasil com a Argentina, registra-se a importante fase das Reduções Jesuíticas. Esta fase reconhecida por Masy (1992) como a origem do Cooperativismo no Rio Grande do Sul caracteriza-se pela organização cooperativada das 18 reduções no território gaúcho. A segunda fase considerada a experiência cabocla, através da qual se buscou constituir uma relação sustentável com a natureza.

A região Missões-Noroeste a colonização tomou impulso com a emancipação de Santo Ângelo (1873), com a conclusão do ramal da via férrea até Cruz Alta (1894) e com a criação das colônias oficiais de Ijuí (1890) e Guarani (1891) e da colônia particular de Cerro Azul (1902). A partir desses primeiros núcleos coloniais foi possível a criação de novas colônias oficiais, como por exemplo Santa Rosa, em 1914, e particulares, como por exemplo Colônia Boa Vista, em 1912. Neste período que se constitui a primeira cooperativa de crédito, pós período de colonização, que a Cooperativa de Crédito Cerro Azul, fundada no ano de 1913, hoje como Sicredi União RS.

As mudanças introduzidas a partir da década de 1940, caracterizadas pela modernização da agricultura e a revolução verde, a sociedade regional se integrou a uma economia de mercado, onde o cooperativismo empresarial passou a crescer e ampliar seu espaço de organização econômica e social. As formas racionais de organização baseadas em cooperativas, sindicatos e associações profissionais passaram a prevalecer frente às formas primárias de solidariedade baseadas na família e na vizinhança. Na operacionalização deste processo foi decisiva a atuação das cooperativas tritícolas e/ou Mistas que foram criadas na região. Elas passaram a atuar como agenciadoras dos programas oficiais de propagação do pacote tecnológico, do financiamento, do armazenamento, da assistência técnica e da orientação aos produtores. Estar ligado a uma cooperativa possibilitou o acesse aos novos modelos produtivos. As cooperativas incorporaram os processos de agro industrialização e de urbano-industrial que começou a se tornar dominante no Brasil na segunda metade do século XX.

Após experimentar décadas de relativo desenvolvimento econômico, impulsionado pela agropecuária e a agroindústria, agregaram-se os desafios da diversificação das atividades produtivas, a reestruturação produtiva e as novas funções para o cooperativismo. A competividade crescente passou a requerer novas competências e a profissionalização das funções gerenciais. $O$ cooperativismo passou a se fazer presente e fortalecer em diferentes ramos, além do agropecuário como, por exemplo, na agricultura o cooperativismo de eletrificação rural e o cooperativismo de crédito rural, e na área urbana, o cooperativismo de transportes, de saúde, de habitação, entre outros. 
No contexto do cooperativismo e do associativismo no âmbito da região protagonizou e agregou novos modelos de organização associativa, com a criação das Associações de Prestação de Serviços e Assistência Técnica - Apsat's e os Condomínios. Estas formas de organização, mesmo com uma duração não muito longa, cumpriram importante contribuição para a produção de suínos e a produção de leite na região, em complemento as tradicionais cooperativas agrícolas existentes na mesma. O espírito associativo, associado a necessidade da organização dos pequenos agricultores focados na diversificação de culturas, foram o nascedouro de várias cooperativas de pequenos agricultores focalizados na agricultura familiar. Estas cooperativas são articuladas na região pela Cooperativa Central das Cooperativas da Agricultura Familiar, a Unicooper (BÜTTENBENDER, 2010a).

O crescimento dos ideais do cooperativismo não é apenas um fenômeno regional. Em nível mundial, como registrado pela ACI (2018) já são mais de 80o milhões de cooperativados, tendo mais de 100 milhões de trabalhadores no Sistema Cooperativo e uma movimentação financeira de mais de US $\$ 65$ bilhões, apenas contando as 300 maiores cooperativas. Em nível de Brasil tem-se mais de 7 milhões de associados, distribuídos por mais de 7.000 cooperativas, gerando mais de 200 mil empregos diretos e respondendo por mais de $6 \%$ do PIB nacional. No Brasil, no início da década de 1990, eram criadas, em média, 6oo cooperativas por ano. A partir do final da década de 1990 este número cresceu para mais de 2.000 por ano. O cooperativismo que era mais presente nas regiões Sudeste, Nordeste e Sul, hoje é um fenômeno disseminado por todo o território nacional. O cooperativismo que estava concentrado em alguns setores (agropecuário, crédito, consumo), hoje é um fenômeno presente em quase todas as áreas da economia e da organização da sociedade (BÜTTENBENDER, 2010a e 2011).

O cooperativismo se incorpora na dinâmica econômica, produtiva e social da região e do estado. Ele está presente nos produtos, serviços, infraestrutura, comercialização, etc. O cooperativismo no Rio Grande do Sul abarca mais de 2,4 milhões de associados, R\$ 28,2 bilhões de faturamento anual e 54,3 mil empregos diretos. O Rio Grande do Sul em 2013 possui 1.041 cooperativas, sendo o estado com maior número de cooperativas registradas na Organização das Cooperativas do Estado do Rio Grande do Sul - OCERGS. No Brasil são 7.132 cooperativas registradas na Organização das Cooperativas Brasileiras - OCB, totalizando mais de 28,3 milhões de associados e 323.856 empregos diretos (Sescoop, 2013).

O cooperativismo ao longo de sua história tem demonstrado as suas positivas contribuições para o desenvolvimento da sociedade, protagonizando e promovendo o direito à cidadania, gerando melhores condições de vida aos que com elas convivem e participam. O cooperativismo fundamenta a sua atuação nos valores da ajuda mútua, responsabilidade, democracia, igualdade, equidade e solidariedade. Por isso está presente no trabalho, na agricultura, na indústria, no comércio, nos serviços, enfim, nos 13 segmentos. O cooperativismo revela ser um dos setores com maior volume de investimentos em prol do desenvolvimento local regional (BÜTTENBENDER, 2010a e 2011).

Os investimentos na qualificação e na educação cooperativa e cidadã dos seus membros lançam sementes e geram frutos para além das fronteiras do cooperativismo, e resultam em proveitos para toda a sociedade. Os associados, dirigentes, funcionários e parceiros são chamados a ampliar as suas capacidades humanas e técnicas, para assim aprimorarem as fortalezas da autogestão cooperativa. A liberdade e a autonomia cooperativa sustentam-se na limitada dependência dos fenômenos econômicos e financeiros externos e na amplitude da capacidade interna (endógena) para gerar respostas cooperativas e modernas aos fatores externos.

A partir dos extratos quantitativos do estudo do RS que considera uma crescente participação da população gaúcha no cooperativismo. Nos últimos 10 anos cresceu de 1,4 milhão de associados para mais de 2,5 milhões. Este número, considerado em unidades familiares e que cada unidade familiar tenha em média três membros, pode-se estimar que no ano de $2014,67,9 \%$ da população gaúcha está envolvida com o cooperativismo. Na região Missões-Noroeste, considerando a 
característica mesmo urbanizada que a média do estado, o histórico de participação cooperativista e a crescente participação do cooperativismo de crédito, este percentual populacional também se reproduz nesse território.

O cooperativismo gaúcho investiu, por exemplo, em 2012, o montante superior a R\$1,7 bilhão, destacando-se como os maiores: agropecuário (agronegócios) com R\$ 809,4 milhões; habitacional com R \$ 480,3 milhões, o crédito com R \$ 133,1 milhões e o de infraestrutura com R \$10o,1 milhões. O cooperativismo de Infraestrutura que se apresenta como o segmento com maior volume de investimentos privados no RS em termos de geração de hidroenergias (SESCOOP, 2012).

O ramo agropecuário das cooperativas, que possuem a maior expressão econômica no RS, abarcam 148 cooperativas, 290 mil associados e 31.148 empregados. Destas cooperativas5o possuem unidades de processamento e transformação de matérias primas, e 67 comercializam algum produto com marca própria. As cooperativas tradicionais possuem suas principais operações voltadas aos grãos.

As práticas inovadoras e de maior agregação de valor estão reservadas ao processamento e na industrialização. No setor lácteo são 42 cooperativas, distribuídas em quase todas as regiões do Estado e que recebem leite. Dessas, 11 possuem plantas de processamento e comercializam leite e seus derivados com marca própria. As cooperativas recebem diariamente 2,2 bilhões de litros leite e industrializam mais de 1,2 bilhão de litros.

No ramo de crédito, considerado um dos mais dinâmicos do sistema, devido a sua expansão e a competitividade do setor. Com um total de 93 cooperativas, distribuídas em 88 cooperativas singulares, 4 centrais e uma confederação. Abarcam um total de 1,6 milhão de associados e 8,2 mil empregados. Em termos de distribuição das cooperativas de crédito por sistema, são relacionadas as cooperativas: 44 Sicredi, 13 Unicred, 11 Cecrers, 6 Crehnor, 1 Sicoob e 18 sem filiação com centrais. Agregam-se aí as cooperativas do Sistema Cooperativas de Crédito de Interação Solidária - Cresol. O Sistema Cresol, com 20 anos de atuação e origem nos três estados do sul do Brasil, ultrapassa os 130 mil associados (CRESOL, 2015).

No Ramo da Saúde, as cooperativas dedicam-se a prestação de serviços e a promoção da saúde humana. Neste ramo as cooperativas dividem-se em médicas, odontológicas, psicológicas e de usuários. O ramo abarca 61 cooperativas, 20,5 mil associados e 9,1 mil empregados. O Sistema Unimed, que opera com mais de 13,6 mil médicos cooperados, 7 Hospitais próprios, 25 prontoatendimentos e um rol de serviços e demais estruturas. São 1,9 milhão de beneficiários com os planos de saúde. O Sistema Uniodonto possui odontólogos 1.700 associados e que atendem 153 mil beneficiários dos planos de assistência odontológica.

O ramo da infraestrutura, que é formado pelas cooperativas de infraestrutura, tradicionalmente conhecidas como cooperativas de eletrificação. Tem como objetivo a distribuição de energia elétrica de geração própria ou compra de concessionárias. O ramo possui 23 cooperativas, sendo uma federação e uma confederação. Atendem a mais de 450 mil associados, em sua maioria da agricultura, distribuídos em 358 municípios do RS. Possuem 62 mil km de extensão de redes próprias de distribuição de energia elétrica. São 3,2 mil empregados vinculados a este ramo. Os investimentos na geração da energia elétrica, através das pequenas centrais hidroelétricas - Pch's destacam o ramo, por se considerado o segmento privado (cooperativo) com maior volume de investimentos na construção de hidroelétricas de pequeno porte no RS desde o ano de 1999. Neste período foram construídas e postas em funcionamento 17 Pch's, com investimentos somados de R\$150 milhões e potência instalada de $49.900 \mathrm{KW}$. Este volume representa o equivalente de $25 \%$ da demanda atual das cooperativas. Neste período as cooperativas investiram mais de R 300 milhões na melhoria de redes de distribuição de energia, melhorando a performance, a redução de perdas e qualidade da energia fornecida. A visão estratégica das cooperativas está com foco na formação de alianças entre 
as cooperativas, com a formação de consórcios, visando à construção de novas usinas, a pesquisa e exploração de novas fontes de geração de energias limpas.

Nos demais ramos do cooperativismo, são considerados: Produção, Transporte, Trabalho, Consumo, Educacional, Habitacional, Turismo e Lazer, Mineral e Especial. Estes ramos, individualmente com menor expressão, mas que no coletivo contribuem de forma positiva no desenvolvimento do cooperativismo e nos aportes ao desenvolvimento.

Registra-se a existência de cooperativas vinculadas à economia solidária e que em sua quase totalidade são de pequeno porte. Situam-se nestas as cooperativas vinculadas a agricultura familiar e que não estão filiadas ao sistema brasileiro de cooperativas. Reconhecida a sua atuação, importância na cooperação, na ajuda mútua e na inclusão social, estão para além do escopo dos objetivos deste estudo. Poderão ser mapeadas e estudadas e futuros e novos estudos.

Além das estatísticas associativas e econômicas dos ramos cooperativos, é relevante destacar o volume crescente de investimentos na educação cooperativa, convergindo com o princípio da educação cooperativa. O aprimoramento cooperativo e sua crescente participação econômica e social, está em um dos seus objetivos estratégicos do sistema, que é no crescente volume de recursos investidos em profissionalização e sustentabilidade do sistema.

No âmbito dos desafios, a evolução das práticas cooperativas ao longo da história, estão ligadas à própria trajetória regional e seu processo de desenvolvimento. O cooperativismo sustenta equilíbrio às relações sociais de produção, associado ao espírito e à cultura cooperativa. $\mathrm{O}$ cooperativismo tem demonstrado as suas positivas contribuições para o desenvolvimento da sociedade, protagonizando o direito à cidadania, gerando melhores condições de vida aos que com elas convivem e participam. O cooperativismo fundamenta a sua atuação nos valores da ajuda mútua e responsabilidade, democracia, igualdade, equidade e solidariedade. Por isso está presente no trabalho, na agricultura, na indústria, no comércio, nos serviços, enfim, nos 13 segmentos. Os investimentos na qualificação e na educação cooperativa e cidadã dos seus membros lançam sementes e geram frutos para além das fronteiras do cooperativismo, e resultam em proveitos para toda a sociedade. Os associados, dirigentes, funcionários e parceiros são chamados a ampliar as suas capacidades humanas e técnicas, para assim aprimorarem as fortalezas da autogestão cooperativa. A liberdade e a autonomia cooperativa sustentam-se na limitada dependência dos fenômenos econômicos e financeiros externos e na amplitude da capacidade interna (endógena) para gerar respostas cooperativas e modernas aos fatores externos.

Orientados por resultados da pesquisa, da interação com o sistema cooperativa e referências de estudos anteriores (BÜTTENBENDER, 1994; BIALOSKORSKI, 2012; RUZZARIN et al, 2010), três fenômenos se salientam e incorporam as prioridades de investimento e demanda estratégica. Assim se posicionam, sem a necessária ordem de importância: a) qualificação dos processos de gestão com a institucionalização de práticas de governança corporativa nas cooperativas, com qualificação dos dirigentes e gestores, referenciando suas práticas de gestão em planos estratégicos de negócios, visando a maior competitividade frente aos demais mercados e a sustentabilidade econômica e corporativa futura das cooperativas; b) promover práticas e ações de maior intercooperação entre cooperativas do mesmo ramo/segmento, bem como entre cooperativas de segmentos diferentes. Esta intercooperação avançando inclusive para ações de fusão e/ou incorporação entre cooperativas, como por exemplo, o agropecuário, visando a racionalização de estruturas meio, otimização de competências e potencialização da competitividade e resultados; c) Na combinação dos dois anteriores, a promoção de investimentos em atividades produtivas de maior agregação de valor, através da industrialização e desenvolvimento de novos produtos e serviços. Estas prioridades fundamentadas pelo vinculo da territorialidade e compromisso com o desenvolvimento econômico, social e sustentável dos seus membros e das regiões onde estão inseridos. 
Na região Missões-Noroeste o cooperativismo possui destacada atuação, com crescente participação na economia regional. Destacam-se como referências positivas de gestão de cooperativas e respectivos ramos cooperativos, como por exemplo: Ceriluz, Cooperluz, Certhil e Coprel, da Infraestrutura; Sicredi, Cresol e Unicred do Crédito; Coopermil, Cotrirosa, Cotricampo, Cotripal no Agropecuário; e Cooperativas de Agricultores vinculados a agricultura familiar.

\section{Considerações finais}

O processo de desenvolvimento territorial, referenciado pelo estado do Rio grande do Sul é marcado ao longo da história por desigualdades regionais. Resultado da ausência de políticas públicas promotoras de um processo de desenvolvimento do estado, alinhados as estratégias nacionais e internacionais, o estado localizado mais ao estremo no território brasileiro, tem a sua dinâmica econômica, social, cultural, tecnológica e ambiental marcada pelas disparidades interregionais e também intrarregionais.

Estes resultados da pesquisa, que corroboram no sentido mais amplo do desenvolvimento com as afirmações de Cargnin et al (2014) ao indicarem que o processo de formação e estruturação das atividades econômico-produtivas do Rio Grande do Sul, e suas consequências sociais, tiveram a importante e decisiva contribuição do processo de organização cooperativo. Desde as bases históricas dos migrantes europeus e a estruturação dos povoados, municípios e regiões, nos diversos espaços geográficos, a presença das organizações cooperativas e suas diferentes formas associativas de organização e produção, foram decisivas para a estruturação econômica, social e cultural. Destacam-se aí as cooperativas mistas de produção, as cooperativas de crédito. As cooperativas de crédito, Caixas de Crédito, inicialmente eram assim denominadas nas regiões de imigração alemã (Na Região Noroeste existiam mais de 20 Sparkassen, citando algumas: Horizontina, Santo Cristo, Crissiumal, Augusto Pestana, Cerro Largo, Santa Rosa, Panambi, entre outras).

Porém, as cooperativas, mesmo com a sua importância e com contribuições aos processos de desenvolvimento local e regional, não foram isoladamente capazes de reverter e contrapor de esvaziamento e empobrecimento relativo da região. As regiões no Rio Grande do Sul, que foram incorporando dinâmicas de desenvolvimento mais fortes, empreenderam a partir de iniciativas mais autóctones, e tiveram no cooperativismo a estratégia e suporte para a estrutura e a organização econômica e social. Estas regiões, como destaca Büttenbender (1995), fomentaram a valorização das dinâmicas internas de organização e participação, promoveram o reinvestimento interno nas regiões e municípios dos valores econômicos gerados e agregados, produziram crescentes níveis e índices de desempenho no trabalho e renda, na educação, na saúde, entre outros.

Estas definições corroboram com aportes de estudos anteriores de Benecke (1980) quando escreve que a forte presença cooperativa promove a elevação cultural e educacional, pratica a cooperação e solidariedade, fortalece a consciência democrática, dinamizam a concorrência e competição, incrementa a geração econômica e distribuição equitativa da renda, combate a exclusão social e promove a paz. Veiga (2006) aporta a definição de que o cooperativismo busca o aprimoramento econômico, social e cultural do ser humano, agregando melhoras nas escalas de poder, transversalidade das políticas públicas com participação da população, auxílio e cooperação das instituições, cooperativas e associações, o fortalecimento das lideranças do território, e o aumento da liberdade e do capital social nas regiões. Já Sen (200o) lavra que o desenvolvimento sustentado no cooperativismo estabelece um processo de expansão das liberdades coletivas da humanidade, pois pelos seus princípios e mecanismos socioeconômicos e institucionais tem como consequência direta a melhora das condições de vida e redução dos índices de pobreza.

A partir do estudo é possível afirmar que o cooperativismo tem relevante importância no processo de desenvolvimento da região Missões-Noroeste. Em determinados períodos de desenvolvimento menos acelerado da região, as cooperativas foram referência na sustentação 
econômica da região e de justificativa de fixação dos empreendedores em suas atividades produtivas, destacando-se a produção primaria.

Evidências vêm demonstrando a relevância dos investimentos em educação, pesquisa e desenvolvimento, gerando novas bases para crescente fixação de jovens no campo e o fortalecimento das atividades produtivas em todos os segmentos produtivos. Os aportes na geração de oportunidades de trabalho e renda e na maior qualificação do universo cooperativo, com repercussões positivas para toda a sociedade, no exercício econômico, político e social. Estes aportes geram contribuições para a melhoria das estruturas de governança nas regiões, expressa ela ativa participa das cooperativas e de seus líderes, por exemplo, em organizações locais regionais, como por exemplo, os Conselhos Regionais de Desenvolvimento - Coredes.

Revela a pertinácia da continuidade dos estudos no âmbito do cooperativismo, que impactam não apenas na qualificação e profissionalização das próprias cooperativas, como também, os aportes para toda a sociedade. O mesmo não permite ilações conclusiva e de generalização destes resultados para outras regiões ou territórios. Assim indica a relevância de realização de novos estudos, abrangendo também outras regiões, bem como, a realização de resultados comparativos. Sugere-se o avanço na pesquisa para identificar, em estudo longitudinal, novos aportes gerados pelo cooperativismo ao processo de desenvolvimento da região.

O estudo revela e subsidia os conceitos de que o cooperativismo, gerido com competência e profissionalismo, com mecanismos de participação, educação e transparência para a sua estrutura corporativa, potencializando os elementos de autogestão do sistema e de governança corporativa, ampliará as suas capacidades de gerar aportes ao desenvolvimento da região Missões Noroeste e a toda a sociedade.

\section{Referências}

ACI. Exploración de la Economía Cooperativa. Word Cooperative Monitor. Informe de 2018. EuricseAliança Cooperativa Internacional. Disponível em: monitor.coop/sites/default/files/publicationfiles/wcm2018es-es-web-656o88611.pdf Acessado em: 22.mar.2019.

ALBUQUERQUE, F. Desarrollo económico local y descentralización en América Latina. In: Revista de la CEPAL, no. 82, abril 2004.

BENECKE, D.W. Cooperação \& Desenvolvimento. Porto Alegre: Coojornal. 1.98o.

BIALOSKORSKI NETO, S. Economia e Gestão de Organizações Cooperativas. $2^{\mathfrak{a}}$ Ed. Atlas. São Paulo. 2012.

BROSE, M. Uma abordagem empírica sobre o desenvolvimento regional, como contribuição para o debate na Região Fronteira Noroeste (RS). In: Capacitação de executivos públicos e agentes sociais para a gestão pública e do processo de desenvolvimento local/regional integrado. Cadernos IPD, n o1, Gestão Públicas, Ijuí: Ed. UNIJUI, 2002.

BUARQUE, S.C. Construindo o desenvolvimento local sustentável. Metodologia de planejamento. Rio de Janeiro: Garamond, 2002.

BÜTTENBENDER, P.L; ROTTA, E.; HOFLER, C.E. O cooperativismo inserido na evolução e no desenvolvimento da Região Fronteira Noroeste. In: Cooperativismo na Região Nordeste do Rio Grande do Sul: experiências de gestão cooperativa e de promoção do desenvolvimento. Porto Alegre, RS: Editora Sescoop, 2010. 
BÜTTENBENDER, P.L. Integração do Associativismo. Cadernos Cedope Unisinos, Editora São Leopoldo. UNISINOS, v. Ano o6. no 12, 1994.

BÜTTENBENDER, P.L. Arranjos institucionais, Cooperação e Desenvolvimento. Redes econômicas, tecnológicas e sociais, sementes do desenvolvimento e agregação de valor. Ijuí/RS : Unijuí, 201ob.

BÜTTENBENDER, P.L. Cooperativismo na Região Nordeste do Rio Grande do Sul: experiências de gestão cooperativa e de promoção do desenvolvimento. Porto Alegre/RS: Editora Sescoop/RS, $2010 a$.

BÜTTENBENDER, P.L. Gestão de Cooperativas. Fundamentos, Estudos e Práticas. Ijuí/RS. Ed.Unijuí, 2011.

BÜTTENBENDER, P.L. O cooperativismo e o desenvolvimento regional: estudo sobre as contribuições das cooperativas e das associações no desenvolvimento da região noroeste. Perspectiva Econômica, n. 36. vol. 29, n. 86, São Leopoldo. Unisinos. 1995.

CARGNIN, A.P. et al . Dinâmicas territoriais recentes no Estado do Rio Grande do Sul. Porto Alegre/RS. Ed. FEE, 2014.

CRESOL. Cooperativas de crédito se destacam no ranking de desembolsos do BNDES. cooperativismodecredito.coop.br/page/2/?s=cresol+2015

Acessado em: 15. de.jun.2016.

DALLABRIDA, V.R.; BÜTTENBENDER, P.L. Gestão, Inovação e Desenvolvimento. Santa Cruz do Sul: Editora UNISC, 2007.

FEE. Base de dados do RS e Regiões. Fundação de Economia e Estatística do Rio Grande do Sul. Porto Alegre. 2015. www.fee.rs.gov.br acessado em 20.03.2015.

FRANTZ, T. R. Cooperativismo empresarial e desenvolvimento agrícola: o caso da COTRIJUÍ. Ijuí: FIDENE, 1982.

FRANTZ, W. Caminhos para o Desenvolvimento pelo Cooperativismo. Ijuí: Unijuí, 2003.

LAKATOS, E.M.; MARCONI, M.A. Fundamentos de metodologia científica. 5. ed. São Paulo: Atlas, 2003.

MASY, R.C. Estrategia de desarrollo rural en los pueblos guaraníes (1609-1767). Barcelona. Instituto de Cooperación Iberoamericana E.A. Bosch. 1992.

OCB. Relatório e Diretrizes aprovados pelo $13^{\circ}$ Congresso Brasileiro de Cooperativismo. OCB, Brasília. 2010. Disponível em: congresso.brasilcooperativo.coop.br/ Acessado em: 20.de.mar.2015.

REISDORFER, V.K. Introdução ao cooperativismo. Santa Maria: Universidade Federal de Santa Maria, Colégio Politécnico, Rede e-Tec Brasil, 2014.

ROTTA, E. Desenvolvimento regional e políticas sociais no noroeste do estado do Rio Grande do Sul. Porto Alegre, FSS/PUCRS, Tese de Doutorado, 2007.

RUZZARIN, A.P.C. et al. O cooperativismo e suas contribuições para o desenvolvimento da região: um estudo a partir da Coopermil. In: Cooperativismo na Região Nordeste do Rio Grande do Sul: experiências de gestão cooperativa e de promoção do desenvolvimento. Porto Alegre/RS : Editora Sescoop/RS, 2010. 
SANTOS, B.S. (Org.). Os caminhos da produção não capitalista. Rio de Janeiro: Civilização Brasileira, 2002.

SCHNEIDER, J.O.; LAUSCHNER, R. O cooperativismo no Brasil: enfoques, análises e contribuições. Porto Alegre, RS: Fundação Friedrich Naumann, 1979.

SEN, A. Desenvolvimento como liberdade. Tradução de Laura Teixeira Motta. São Paulo. Ed. Companhia das Letras. 2000.

SESCOOP/RS. Expressão do Cooperativismo Gaúcho. Porto Alegre/RS. Ed. Sescoop. 2012.

SESCOOP/RS. Expressão do Cooperativismo Gaúcho. Porto Alegre/RS. Ed. Sescoop. 2013.

SIEDENBERG, D.R. (org.). Dicionário do Desenvolvimento Regional. Santa Cruz do Sul: Edunisc, 2006.

STUMPF, I. R. C. Pesquisa bibliográfica. In A. Barros; J. Duarte (Orgs.), Métodos e técnicas de pesquisa em comunicação. São Paulo: Atlas, 2005. pp.51-61.

VEIGA, J.E. Desenvolvimento Sustentável: um desafio do século XXI. Rio de Janeiro, Ed. Garamond. 2006.

VEIGA, S.M.; FONSECA, I. Cooperativismo uma revolução pacífica em ação. Rio de Janeiro: DP\&A, 2001.

YIN, R.K. Estudo de caso: planejamento e métodos. 3. ed. Porto Alegre: Bookman, 2005. 